\title{
Strategies to improve HIV treatment adherence in developed countries: clinical management at the individual level
}

This article was published in the following Dove Press journal:

HIVIAIDS - Research and Palliative Care

16 May 20II

Number of times this article has been viewed

\author{
Maithe Enriquez' \\ David S McKinsey² \\ 'School of Nursing, University of \\ Missouri-Kansas City and Division of \\ Infectious Diseases, Truman Medical \\ Center Hospital Hill, ${ }^{2}$ School of \\ Medicine, Division of Infectious \\ Diseases, University of Kansas and \\ Division of Infectious Diseases, \\ Research Medical Center, Kansas City, \\ MO, USA
}

Correspondence: Maithe Enriquez 2406 Health Sciences Building, 2464 Charlotte Street, Kansas City, MO 64108, USA

Tel +1816235 I7II

Fax + | 816235 |70|

Email enriquezm@umkc.edu

\begin{abstract}
Remarkable advances in the treatment of human immunodeficiency virus (HIV) disease have been blunted by widespread suboptimal adherence (ie, nonadherence), which has emerged as a major barrier to achieving the primary goal of antiretroviral (ARV) therapy: suppression of HIV viral load. Nonsuppressed HIV viral load is associated with drug resistance, increased morbidity and mortality, and a higher risk of person-to-person HIV transmission. For HIV-infected individuals who are failing HIV treatment due to nonadherence, becoming adherent is a life-saving behavior change. However, overcoming nonadherence is one of the most daunting challenges in the successful management of HIV disease. The purpose of this paper is to provide clinicians with a better understanding of nonadherence to ARV treatment and to review the various factors that have been associated with either adherence or nonadherence. Strategies are presented that may help the nonadherent individual become ready to take HIV medications as prescribed.
\end{abstract}

Keywords: noncompliance, treatment failure, AIDS

\section{Introduction}

Human immunodeficiency virus (HIV) disease is one of the most important global health problems. ${ }^{1}$ Untreated HIV infection causes progressive deterioration of the immune system (ie, AIDS), which results in substantial morbidity and mortality. Efficacious antiretroviral (ARV) treatment has transformed HIV, once considered invariably fatal, into a chronic manageable disease; however, nonadherence has emerged as a major barrier to successful treatment of this disease.

The positive impact of ARV therapy, in developed countries, has been striking. The median life expectancy for a 25 -year old newly HIV-infected individual who has access to ARV treatment is an additional 39 years. ${ }^{2}$ Large observational cohort studies have shown that starting ARV sooner in the course of HIV disease is associated with a significant reduction in mortality. ${ }^{3}$ Furthermore, ARV therapy also decreases complications from HIV-associated inflammation and significantly reduces the risk for transmission of HIV in serodiscordant couples. ${ }^{4} \mathrm{ARV}$ treatment has become so effective that a strategy to use universal HIV testing and early initiation of ARV therapy as a method of eradicating the disease has been proposed. ${ }^{5}$ These overwhelming benefits of ARV therapy, coupled with its cost-effectiveness, led to the December 1, 2009, Department of Health and Human Services (DHHS) recommendation to start ARV treatment earlier in the course of HIV disease. ${ }^{6}$ Thus the number of individuals who are prescribed ARV therapy has increased, 
and strategies for enhancement of adherence in this growing population require careful attention.

Numerous studies have shown that the key to HIV treatment success is suppression of HIV viral load by ensuring that HIV-infected individuals not only have full, uninterrupted access to ARV medications but also take them consistently every day of their lives. ${ }^{6}$ Interruptions in ARV therapy and missing medication doses are associated with a high risk for nonsuppressed HIV viral load, leading to drug resistance and consequent treatment failure. ${ }^{7}$ Individuals who develop drug resistance due to suboptimal adherence (ie, nonadherence) to their ARV medication regimens are challenging to treat, require more complex and costly ARV medication combinations to suppress HIV viral load, are hospitalized significantly more frequently than their adherent counterparts, ${ }^{8}$ and experience extremely poor health outcomes and low quality of life..$^{9,10}$ Although new ARV medications are more 'forgiving' (ie, do not seem to require such strict adherence as was necessary with older ARV regimens), ${ }^{11}$ the ability to take ARV medications consistently remains the key factor in ensuring positive HIV-related health outcomes and improving quality of life. ${ }^{12}$

\section{The problem of nonadherence to HIV treatment}

While many HIV-infected individuals are able to successfully take their ARV medications as prescribed, over onethird $(37 \%)$ of HIV-infected persons in developed countries have difficulty maintaining adequate levels of adherence. ${ }^{13}$ Although developing countries have reported lower rates of nonadherence, newer studies have indicated that the problem of nonadherence is global. ${ }^{14}$ The inability of clinicians to predict adherence among their patients has been disappointing. No currently available screening tools can reliably prospectively identify those individuals who will be either adherent or nonadherent. Adherence is highest among treatment-naïve individuals, who are presumably more motivated and less "fatigued" with their medication regimens. Adherence is enhanced by the use of potent antiretroviral regimens with a low daily pill count, especially when prescribed either once or twice a day. ${ }^{15}$

The nonadherent subset of the HIV population has presented one of the most daunting challenges in the successful long-term management of HIV disease. The etiology of nonadherence is generally multi-faceted, as will be discussed below. Nonadherence promotes the development of drug resistance mutations and necessitates use of more complex ARV regimens. ${ }^{9}$ Individuals who are nonadherent to ARV medications experience immune system deficiency and develop persistent debilitating constitutional symptoms such as fevers, night sweats, weight loss, and diarrhea. ${ }^{16}$ Their risk for life-threatening opportunistic infections increases. ${ }^{16}$ Further, untreated HIV causes an inflammatory process that damages vital organ systems resulting in increased morbidity. ${ }^{17}$ Finally, HIV-infected individuals with nonsuppressed HIV viral load are at much higher risk for transmitting HIV to others. ${ }^{4}$

In addition to the negative impact of nonadherence on individual health, the financial burden of nonadherence is also substantial. As HIV-infected individuals fail ARV regimens, each subsequent medication regimen becomes not only more complex but also more costly because a greater number of medications are needed to suppress HIV viral load. ${ }^{18}$ The ARV medications currently available to treat HIV disease are used in a strategic order and in well-defined combinations to ensure efficacy. ${ }^{19}$ While first-line ARV regimens typically consist of one to three pills taken once daily, regimens for individuals with drug resistance are usually dosed twice a day and entail use of a much larger number of medications with a higher total daily pill count. ${ }^{6}$ More complicated third and fourth line ARV regimens often cause more side effects and toxicities. ${ }^{6}$ In addition, drug resistance also increases associated health care costs. Not only do the more complicated regimens cost more but additional expensive laboratory tests, such as genotypes and phenotypes, are required to assess the degree and type of HIV drug resistance to make appropriate prescribing decisions about alternate efficacious ARV regimens. ${ }^{20}$

\section{The science of HIV treatment adherence}

There is a plethora of published data documenting that, for HIV-infected individuals who experience problems taking ARV medications as prescribed, becoming adherent to ARV therapy is a life-saving behavior change. ${ }^{6,21}$ If the cycle of nonadherence to ARV treatment can be broken, particularly at an early stage, there are many far-reaching positive implications. For a nonadherent person, the ability to become adherent can mean the difference between experiencing complex, costly health problems and poor quality of life as opposed to enhanced health outcomes and a productive life. In addition, costs to the health care system are reduced as described above, and the risk of HIV transmission to the community at large is reduced. Given the importance of 
diligent ARV adherence for the suppression of HIV viral load and treatment success, a number of studies have been conducted to improve our understanding of the phenomenon of adherence and to develop strategies that enhance individual adherence behavior.

\section{Barriers and facilitators to HIV treatment adherence}

Researchers have identified multiple factors associated with the inability, and the ability, to take ARV medications as prescribed $^{15,22-38}$ (ie, barriers and facilitators to adherence, see Table 1). Facilitators of adherence improve the ability to take ARVs as prescribed while barriers are associated with the inability to take ARVs consistently. These factors appear to be consistent across different populations of people living with HIV. Known barriers to HIV treatment adherence fall into several broad categories including psychosocial issues, economic factors, substance abuse, co-morbidities including psychiatric disease, low health literacy, or medication-related issues (ie, interference with lifestyle, side effects, or undue complexity). Many of these factors are modifiable, or at least partially modifiable, with appropriate intervention. Conversely, categories of facilitators of adherence include personal motivation, support systems, organizational skills, and a convenient and well-tolerated ARV medication regimen. These known facilitators of adherence can be used to enhance adherence to ARV therapy.

\section{HIV treatment adherence interventions}

Many important HIV adherence intervention studies have been conducted. A variety of strategies to enhance adherence have been tested in noncontrolled, controlled, and randomized controlled studies. ${ }^{39-51}$ Adherence has been measured in various ways such as self-report, electronic devices (ie, MEMS), pharmacy refill logs, pill counting, or a combination of these measures. The critically important biologic markers of ARV treatment efficacy, which are typically used in clinical practice, have also been used to examine the impact of adherence interventions in some research studies. However, most adherence studies have not included these laboratory markers (eg, HIV viral load and CD4 cell count) as outcome measures. Several randomized controlled trials have reported positive results on adherence intervention (ie, an increase in the rate of adherence) on behavioral measures such as self-report or pill counts. However, results with regard to intervention impact on HIV viral load suppression and increase in CD4 cell count have been less encouraging. Successful strategies to enhance adherence have included cognitive and behavioral strategies, directly observed therapy (DOT), modified DOT, peer support and effective strategies that enhance the known facilitators of adherence to ARV therapy.

Despite the large amount of literature focusing on HIV treatment adherence, the subset of the HIV-infected population with known nonadherence problems has been underrepresented in adherence intervention research. Those individuals who have failed HIV treatment repeatedly, who are particularly challenging and expensive to manage and who likely have the most to gain from becoming adherent have often been excluded or not targeted in adherence research. Indeed, a meta-analysis that synthesized findings of HIV adherence interventions tested in randomized

Table I Barriers and facilitators of ARV therapy adherence ${ }^{15,22-38}$

\section{Barriers}

- Substance abuse

- Fear of disclosure of HIV status

- Denial of the HIV diagnosis

- Speaking a different language than the health care provider

- Stigma

- Depression

- Forgetfulness

- Suspicions about ARV treatment

- ARV regimens that are considered to be too complicated

- Perceived unpleasant side-effects from ARV medications

- High number of pills in an ARV regimen

- Sleeping through medication dosing time

- Decreased quality of life

- Work and family responsibilities

- Limited access to ARV medications

\section{Facilitators}

- Sense of self-worth

- Seeing/feeling positive effects of ARV therapy

- Strong will to live

- Acceptance of the HIV diagnosis

- Understanding the need for adherence

- Making use of reminder tools such as pill organizers

- Having an ARV regimen that "fits" into one's daily schedule

- Once daily dosing of ARV medications

- Presence of motivational readiness

- Perception of a positive health care provider-patient relationship

- Having social support 
controlled trials (RTCs) between 1996 and 2004 reported stronger intervention effect when participants with known adherence problems were targeted. ${ }^{39}$ The exclusion of nonadherent individuals from HIV treatment adherence trials unfortunately has resulted in limited knowledge about effective strategies to enhance adherence for this vulnerable group.

\section{Readiness for adherence}

Perhaps the most important personal (ie, individual level) component of adherence is the role of motivational readiness on an individual's ability to adhere to HIV treatment as prescribed. The 2011 DHHS Guidelines, the 2010 International AIDS Society Guidelines, and the current European AIDS Society guidelines for the use of antiretroviral agents in HIV-1 infected adults and adolescents recommend that ARV therapy should be initiated only when an HIV-infected individual is "ready" to adhere to ARV medications. Readiness occurs when an individual, of his or her own free will, reaches a conscious awareness that a particular behavior is desired and beneficial. ${ }^{52}$ Readiness has been identified as a critical component in a number of healthful behaviors such as cessation of excessive alcohol consumption, ${ }^{53}$ adoption of asthma treatment strategies, ${ }^{54}$ and improvement with anger management treatment. ${ }^{55}$ Some theorists consider change and readiness to be nearly the same phenomenon ${ }^{56}$ while others purport that readiness is a separate stage that precedes change and is necessary for healthful behavior modification to occur. ${ }^{57}$ The presence of readiness has been shown to be an important predictor of ARV medication adherence. Higher motivational readiness prior to starting ARV therapy has been associated with subsequent adherence. ${ }^{58}$

The literature has emphasized the importance of readiness and its significant role in HIV treatment adherence success. ${ }^{59-61}$ Placebo practice trials have been suggested as a method to predict readiness for ARV adherence among HIV-infected substance dependent individuals. ${ }^{62}$ However, there are currently no standardized validated measures of HIV treatment readiness for use in clinical practice. Further, the impact of an individual's level of readiness on subsequent HIV treatment adherence has not been rigorously studied in randomized controlled trials. Of note is one randomized controlled trial of a psychoeducational intervention that aimed to improve psychological readiness for ARV medication adherence and reduce depression. ${ }^{63}$ Participants in the intervention group had higher readiness scores and lower depression scores 4 weeks post-baseline than the control group. While results were encouraging, the follow-up period was short, long-term adherence after initiation of ARV treatment was not examined, and HIV viral load suppression was not assessed.

\section{Enhancement of readiness for HIV treatment adherence}

Individuals who have problems taking HIV treatment as prescribed may lack readiness for the rigors of taking lifelong ARV medications. Motivational readiness was first proposed as a necessary precursor to individual ability to adhere to ARV treatment in $1998 .{ }^{52}$ Several readiness and adherence studies have demonstrated that readiness is an important predictor and critical component in the initiation and maintenance of healthful ARV adherence behavior. ${ }^{51,58,63}$ Moreover, clinical screening tools, such as the Index of Readiness scale, have been tested in small studies and have promise for use in the clinical setting. ${ }^{64}$

\section{Conclusions and implications}

Although there is no single strategy for enhancement of adherence that can be applied in every clinical setting, based on our clinical experience and the results of our HIV treatment adherence research, ${ }^{27,51,52,58}$ we offer various approaches for consideration by individual clinicians:

- an assessment of readiness for adherence before initiating treatment with ARV naive patients, and again if treatment failure occurs and a new regimen is prescribed;

- identification of barriers to adherence;

- provide help to the nonadherent individual to facilitate the creation of practical strategies to overcome barriers to adherence (ie, avenues to build social support networks, to enhance the patient-provider relationship, and to provide consistent interaction);

- ask the patient to make a list of his/her barriers to adherence in rank order and begin by addressing the barrier to adherence that the individual identifies as the "easiest" to overcome;

- use potent antiretroviral regimens in accordance with current treatment guidelines;

- when possible, utilize once-daily regimens with low pill counts;

- identify and address substance abuse issues prior to initiation of ARV treatment if feasible;

- treat depression and other mental illnesses. 
Highly effective ARV medications are available for the treatment of HIV disease. Such treatment affords HIVinfected individuals the potential for long, healthy, and productive lives. However, management of HIV disease is often difficult due to the complex psychosocial issues, co-morbid conditions, and socioeconomic challenges that impact many individuals who are infected with HIV. In our 25 years as providers on the "front-line" we have cared for more HIV-infected individuals who experienced problems with adherence to their ARV therapy than we could have imagined. Our experience has been that utilization of the individualized strategies that we have summarized in this paper, together with a team approach to HIV care, has led to the best patient outcomes. ${ }^{65}$

Despite modest progress in the area of HIV treatment adherence, clearly more research is required to improve adherence on a much larger scale ${ }^{66}$ Clinicians would welcome a simple, yet effective, screening tool for use before initiating ARV therapy to help them identify patients who may be at-risk for suboptimal adherence. In addition, HIV treatment adherence interventions that can be tailored to specific subgroups of individuals who are failing ARV treatment, and that are practical for implementation in the majority of HIV care settings, are urgently needed.

\section{Acknowledgments}

We thank the members of the HIV care teams at Truman Medical Center, Research Medical Center and Infectious Disease Associates for their dedication and expertise and also for being such great colleagues.

\section{Disclosure}

No conflicts of interest were declared in relation to this paper.

\section{References}

1. Fauci AS, Folders GK. Investing to meet the scientific challenges of HIV/AIDS. Health Aff. 2009;28:1629-1641.

2. Lohse N, Hansen A, Penersen G, et al. Survival of persons with and without HIV infection in Denmark, 1995-2005. Ann Intern Med. 2007; 146:87-95.

3. Kitahata J, Gange SJ, Abraham AG, et al; for the NA-ACCORD Investigators. Effect of early versus deferred antiretroviral therapy for HIV on survival. $N$ Engl J Med. 2009;360:1815-1826.

4. Sullivan P, Kayitenkore K, Chomba E, et al. Reduction of HIV transmission risk and high risk sex while prescribed ART: results from discordant couples in Rwanda and Zambia, Abstract 52bLB, 16th Conference on Retroviruses and Opportunistic Infections: San Francisco, CA; October 6, 2009.

5. Granich RM, Gilks CF, Dye C, DeCock KM, Williams BG. Universal voluntary HIV testing with immediate antiretroviral therapy as a strategy for elimination of HIV transmission: a mathematical model. Lancet. 2009;373:48-57.
6. [DHSS] Department of Health and Human Services. Panel on antriretroviral guidelines for adults and adolescents. Guidelines for the use of antiretroviral agents in HIV-1 infected adults and adolescents. January 10, 2011. Available at http://aidsinfo.nih.gov/contentfiles/ AdultandAdolescentGL.pdf. Accessed March 25, 2011.

7. Ananworanich J, Gayet-Ageron A, LeBraz M, et al. CD-guided scheduled treatment interruptions compared with continue therapy for patients infected with HIV-1: results of the Staccato randomized trial. Lancet. 2006;368:459-465.

8. Sax PE, Meyers J, Mugaver M, Davis KL. Adherence to antiretroviral treatment regimens and correlation with risk of hospitalization among commercially insured HIV patients in the United States. $J$ Int AIDS Society. 2010;13(Suppl 4):03.

9. Clavel F, Hance AJ. HIV drug resistance. $N$ Eng $J$ Med. 2004;350: 1023-1035.

10. Bangsberg DR, Perry S, Charlebois ED, et al. Nonadherence to highly active antiretroviral therapy predicts progression to AIDS. AIDS. 2001; 15:1181-1183.

11. Shuter J. Forgiveness of non-adherence to HIV-1 antiretroviral therapy. J Antimicrob Chemother. 2008;61:769-773.

12. Mills E, Nachega JB, Buchan I, et al. Adherence to antiretroviral therapy in sub-Saharan African and North America. JAMA. 2004;296: 679-690.

13. Bonolo PF, Machado CJ, Cesar CC, Ceccato MG, Guimaraes MD. Vulnerability and non-adherence to antiretroviral therapy among HIV patients Minas Gerais State, Brazil. Cad Saude Publica. 2008;24:2603-2613.

14. Uzochukwu BSC, Onwujekwe OE, Onoka AC, Okoli C, Uguru NP, Chukwuogo OI. Determinants of non-adherence to subsidized anti-retroviral treatment in southeast Nigeria. Health Policy Plan. 2009;24:189-196.

15. DeJesus E, Young B, Morales-Ramirez JO, et al. for the AI266073 Study Group. Simplification of antiretroviral therapy to a single-tablet regimen consisting of efavirenz emtricitabine and tenofovir disoproxil fumuarate versus unmodified antiretroviral therapy in virologically suppressed HIV-1-infected patients. J Int AIDS Society. 2009;51:163-174.

16. Mandell GL, Bennett JE, Dolin R. Mandell Douglas and Bennett's principles and practice of infectious diseases. 7 th ed. Philadelphia, PA: Churchill Livingstone Elsevier; 2009.

17. McComsey G, Smith K, Patel P, et al. Similar reductions in markers of inflammation and endothelial activation after initiation of abacavir/ lamivudine or tenofovir/emtricitabine: the HEAT study. Paper presented at: 16th Conference on Retroviruses and Opportunistic Infections: Montreal, QC; 2009.

18. Campbell T, Shulman N, Johnson S, et al. Antiviral activity of lamivudine in salvage therapy for multidrug-resistant HIV-1 infection. Clin Infect Dis. 2005;41:236-242.

19. Torti C, Quiros-Roldan E, Regazzi M, et al; and the RADAR-MASTER Group. A randomized controlled trial to evaluate antiretroviral salvage therapy guided by rules-based or phenotype-driven HIV-1 genotypic drug-resistance interpretation with or without concentration-controlled intervention: the resistance and dosage adapted regimens (RADAR) study. Clin Infec Dis. 2005;40:1828-1836.

20. Hughes A, Barber T, Nelson M. New treatment options for HIV salvage patients: an overview of second generation PIs, NNRTIs, integrase inhibitors and CCR5 antagonists. $J$ Infect. 2008;57:1-10.

21. Taiwo B. Adherence to antiretroviral therapy: the more you look, the more you see. Curr Opin HIV AIDS. 2009;4:488-492.

22. Wood E, Kerr T, Tyndall MW, Montaner JS. A review of barriers and facilitators of HIV treatment among injection drug users. AIDS. 2008; 22:1247-1256.

23. Konkle-Parker DJ, Erlen JA, Dubbert PM. Barriers and facilitators to medication adherence in a southern minority population with HIV disease. J Assoc Nurses AIDS Care. 2008;19:98-104.

24. Dahab M, Charalambous S, Hamilton R, et al. "That is why I stopped the ARV": patients' and providers' perspectives on barriers to and enablers of HIV treatment adherence in a South African workplace programme. BMC Public Health. 2008;18:63. 
25. Watt MH, Maman S, Earp E, Setel P, Golin CE, Jacobson M. "It's all the time in my mind": facilitators of adherence to antiretroviral therapy in a Tanzanian setting. Soc Sci Med. 2009;68: 1793-1800.

26. Edwards LV. Perceived social support and HIV/AIDS medication adherence among African American women. Qual Health Res. 2006; 16:679-691.

27. Enriquez M, Lackey NR, O’Connor MC, McKinsey DS. Successful adherence after multiple HIV treatment failures. J Adv Nurs. 2004; 45:438-446.

28. MacDonell KE, Naar-King S, Murphy DA, Parsons JT, Harper GW. 2009. Predictors of medication adherence in high risk youth of color living with HIV. J Pediatric Psychol. 2010;35:593-601.

29. Sanjobo N, Frich JC, Fretheim A. Barriers and facilitators to patients' adherence to antiretroviral treatment in Zambia: a qualitative study. SAHARA. 2008;5:135-143.

30. Starks S, Simoni J, Zhao H, et al. Conceptualizing antiretroviral adherence in Beijing, China. AIDS Care. 2008;20:607-614.

31. Kumarasamy N, Safren SA, Raminani SR, et al. Barriers and facilitators to antiretroviral medication adherence among patients with HIV in Chennai, India: a qualitative study. AIDS Patient Care STDS. 2005;19: 526-537.

32. Remien RH, Hirky AE, Johnson MO, Weinhardt LS, Whittier D, Le GM. Adherence to medication treatment: a qualitative study of facilitators and barriers among a diverse sample of HIV+ men and women in four US cities. AIDS Behav. 2003;7:61-72.

33. Golin CE, Honghu L, Hays RD, et al. A prospective study of predictors of adherence to combination antiretroviral medication. J Gen Int Med. 2002; 17:756-765.

34. Gordillo V, delAmo J, Soriano V, Gonazlez-Lahoz J. Sociodemographic and psychological variables influencing adherence to antiretroviral therapy. AIDS. 1999;13:1763-1769.

35. Ostrop N, Halett K, Gill J. Long-term patient adherence to antiretroviral therapy. Ann Pharmacother. 2000;34:703-709.

36. Ickovics JR, Cameron A, Zackin R, et al. Consequences and determinants of adherence to antiretroviral mediation: results from Adult AIDS Clinical Trials Group protocol 370. Antivir Ther. 2002;7: 185-193.

37. Schneider J, Kaplan S, Greenfield S, et al. Better physician-patient relationships are associated with higher reported adherence to antiretroviral therapy in patients with HIV infection. J Gen Intern Med. 2004;19: 1096-1103.

38. Gonzalez JS, Penedo FJ, Antoni MH, et al. Social support, positive states of mind and HIV treatment adherence in men and women living with HIV/AIDS. Health Psychol. 2004;23:413-418.

39. Amico KR, Harman JJ, Johnson BT. Efficacy of antiretroviral interventions: a research synthesis of trials, 1996 to 2004. J Acquir Immune Defic Syndr. 2006;41:285-297.

40. Simoni J, Frick P, Pantalone D, Turner B. Antiretroviral adherence interventions: a review of current literature and ongoing studies. Top HIV Med. 2003;11:185-198.

41. Simoni J, Pearson C, Pantalone D, Marks G, Crepaz C. Efficacy of interventions in improving highly active antiretroviral therapy adherence and HIV-1 RNA viral load. J Acquir Immune Defic Syndr. 2006; 43(Suppl 1):S23-S35.

42. Safren SA, O'Cleirigh C, Tan JY, et al. A randomized controlled trial of cognitive behavioral therapy for adherence and depression (CBT-AD) in HIV-infected individuals. Health Psychol. 2009;28:1-10.

43. Koenig LJ, Pals SL, Bush T, Pratt M, Stratford D, Ellerbrock TV. Randomized controlled trial of an intervention to prevent adherence failure among HIV-infected patients initiating antiretroviral therapy. Health Psychol. 2008;27:159-169.

44. Remien RH, Stirratt MJ, Dolezal C, et al. Couple-focused support to improve HIV medication adherence: a randomized controlled trial. AIDS. 2005;19:807-814.
45. Simoni JM, Huh D, Frick PA, et al. Peer support and pager messaging to promote antiretroviral modifying therapy in Seattle: a randomized controlled trial. J Acquir Immune Defic Syndr. 2009;52:465-473.

46. Liu H, Golin E, Miller L, et al. A comparison study of multiple measures of adherence to HIV protease inhibitors. Ann Intern Med. 2001;134: 968-977.

47. Andrade ASA, McGruder HF, Wu A, et al. A programmable prompting device improves adherence to highly active antiretroviral therapy in HIV-infected subjects with memory impairment. Clin Infec Dis. 2005;41:875-882.

48. Rathbun RC, Farmer KC, Stephens JR, Lockhart SM. Impact of an adherence clinic on behavioral outcomes and virologic response in treatment of HIV infection: a prospective, randomized, controlled pilot study. Clin Ther. 2005;27:199-209.

49. Rawlings MK, Thompson MA, Farthing CF, et al. Impact of an educational program on efficacy and adherence with a twice-daily lamivudine/ zidovudine/abacavir regimen in underrepresented $\mathrm{HIV}$-infected patients. J Acquir Immune Defic Syndr. 2003;34:174-183.

50. Tuldra A, Fumaz CR, Ferrer MJ, et al. Prospective randomized two-arm controlled study to determine the efficacy of a specific intervention to improve long-term adherence to highly active antiretroviral therapy. J Acquir Immune Defic Syndr. 2000;25:221-228.

51. Enriquez M, Cheng AL, McKinsey DS, Stanford J. Development and efficacy of an intervention to enhance readiness for adherence among adults who had previously failed HIV treatment. AIDS Patient Care STDS. 2009;23:177-184

52. Fowler ME. Recognizing the phenomenon of readiness: concept analysis and case study. J Assoc Nurses AIDS Care. 1998;9:72-76.

53. Stein LA, Minugh PA, Longabaugh R, et al. Readiness to change as a mediator of the effect of a brief motivational intervention on post treatment alcohol-related consequences of injured emergency department hazardous drinkers. Psychol Addict Behav. 2009;23:185-195.

54. Fisher EB, Strunk RC, Highstein GR, et al. A randomized controlled evaluation of the effect of community health workers on hospitalization for asthma: the asthma coach. Arch Pediatr Adolesc Med. 2009;163: 225-232.

55. Helestine K, Howells K, Day A. Brief anger interventions with offenders may be ineffective: a replication and extension. Behav Res Therapy. 2010;48:246-250.

56. DiClimente C, Prochaska J. Processes and stages of self-change: coping and competence in smoking behavior change. In Shiffman S, Willis T, editors. Coping and substance abuse. Orlando, FL: Academic Press; 1985:319-343.

57. Blumer H. Symbolic interactionism: perspective and method. Englewood Cliffs, NJ: Prentice Hall; 1969.

58. Enriquez M, Gore PA, O'Connor MC, McKinsey DS. Assessment of readiness for adherence by HIV-positive males who had previously failed treatment. J Assoc Nurses AIDS Care. 2004;15:42-49.

59. Gebrekristos HT, Mlisana KP, Krim QA. Patients' readiness to start highly active antiretroviral treatment for HIV. Br Med J. 2005;331: $772-775$.

60. Alfonso V, Toulson A, Bermbach N, Erskine Y, Montaner J. Psychosocial issues influencing treatment adherence in patients on multidrug rescue therapy: perspectives from patients and their health care providers. AIDS Patient Care STDS. 2009;23:119-126.

61. Nordqvist O, Sodergard B, Tully MP, Sonnerborg A, Lindblad AK. Assessing and achieving readiness to initiate HIV medication. Patient Educ Couns. 2006;62:21-30.

62. Wagner G. Placebo practice trials: the best predictor of adherence readiness for HAART among drug users? HIV Clin Trials. 2003;4: 269-281.

63. Balfour L, Lowal J, Silverman A, et al. A randomized controlled psychoeducation intervention trial: improving psychological readiness for successful HIV medication adherence and reducing depression before initiating HARRT. AIDS Care. 2006;18:830-838. 
64. Fleury J. The index of readiness: development and psychometric analysis. J Nurs Manag. 1994;31:470-477.

65. Enriquez M, Farnan R, Cheng A, et al. Impact of a bilingual/bicultural care team on HIV-related health outcomes. J Assoc Nurses AIDS Care. 2008;19:295-301.
66. Grimes RM, Grimes DE. Readiness: the state of the science (or the lack thereof). Curr HIV/AIDS Rep. 2010;7:245-252.

HIV/AIDS - Research and Palliative Care

\section{Publish your work in this journal}

HIV/AIDS - Research and Palliative Care is an international, peerreviewed open-access journal focusing on advances in research in HIV, its clinical progression and management options including antivira treatment, palliative care and public healthcare policies to contro viral spread. The journal welcomes original research, basic science, clinical \& epidemiological studies, reviews \& evaluations, expert opinion \& commentary, case reports \& extended reports. The manuscript management system is completely online and includes a very quick and fair peer-review system. Visit http://www.dovepress.com/ testimonials.php to read real quotes from published authors.

Submit your manuscript here: http://www.dovepress.com/hivaids---research-and-palliative-care-journal 